\author{
Bambang Sugiyanto \\ Balai Arkeologi Provinsi Maluku \\ Jalan Namalatu-Latuhalat, \\ Kecamatan Nusaniwe, Kota \\ Ambon, Maluku, Indonesia; \\ posel: bsugiyanto@gmail.com
}

Diterima 28 Agustus 2020

Direvisi 3 November 2020

Disetujui 5 November 2020

\section{PENEMUAN ROCK ART BARU DI KAWASAN KARST DESA REJOSARI, KECAMATAN MANTEWE, KABUPATEN TANAH BUMBU, PROVINSI KALIMANTAN SELATAN}

\author{
THE NEW FINDING OF ROCK ART IN THE KARST AREA OF \\ REJOSARI VILLAGE, MANTEWE DISTRICT, TANAH BUMBU \\ REGENCY, SOUTH KALIMANTAN PROVINCE
}

\begin{abstract}
Abstrak. Kawasan karst di Desa Rejosari, Kecamatan Mantewe, Kabupaten Tanah Bumbu, Provinsi Kalimantan Selatan, merupakan bagian dari gugusan karst Mantewe yang membentang luas. Penelitian arkeologi prasejarah pada kawasan karst ini sudah dimulai sejak tahun 2008, di wilayah Desa Mantewe, Desa Bulurejo, Desa Dukuhrejo, dan Desa Rejosari. Potensi budaya prasejarah yang ada pada kawasan karst Mantewe, sangat bagus, seperti situs Gua Sugung (Desa Mantewe), Gua Payung (Desa Bulurejo), dan Gua Bangkai (Desa Dukuhrejo), serta gambar cadas dengan warna hitam pada beberapa gua dan ceruk terutama pada kawasan karst Desa Dukuhrejo. Permasalahan dalam penenelitian ini adalah apakah budaya rock art itu juga ada pada kawasan karst di Desa Rejosari. Metode survei dan ekskavasi dilakukan dalam proses pengumpulan data. Hasil penelitian memperlihatkan adanya kekayaan lukisan dinding gua di Rejosari, yang dapat digunakan untuk melengkapi data arkeologi prasejarah yang ada pada kawasan karst Mantewe secara umum, termasuk budaya rock art yang ada di dalamnya.
\end{abstract}

Kata Kunci: lukisan dinding gua, karst, Tanah Bumbu, Kalimantan Selatan

\begin{abstract}
The karst area in Rejosari Village, Mantewe District, Tanah Bumbu Regency, South Kalimantan Province, is the stretches out wide part of Mantewe karst cluster. Prehistoric archaeological researches on this karst area have been conducted since 2008, starting from the karst area of Mantewe Village, Bulurejo Village, Dukuhrejo Village, and in 2018 was entering Rejosari Village area. The potential of prehistoric culture in the karst is remarkable, such as the existences of Sugung Cave (Mantewe Village), Payung Cave (Bulurejo Village), and Bangkai Cave (Dukuhrejo Village), and also the black of rock art or rock drawings in some caves and niches, especially in Dukuhrejo Village. An interesting issue is filed in this research is whether the rock art culture also exists in Rejosari Village. The method of survey and excavation were used for collecting data in Rejosari karst area. The results suggest that rock art at Rejosari are treasure that can be complement the existing prehistoric archaeological data in the Mantewe karst area in general, including the rock art culture that exists therein.
\end{abstract}

Keyword: rock-art, karst, Tanah Bumbu, South Kalimantan

\section{PENDAHULUAN}

Pegunungan Meratus yang membelah Provinsi Kalimantan Selatan, mempunyai kekayaan kawasan karst yang begitu besar. Kawasan karst tersebut berada di Kabupaten Tabalong di bagian utara, terus ke selatan timur (tenggara) pada Kabupaten Tanah Bumbu. Kawasan karst ini menawarkan geomorfologi lingkungan yang cukup ramah bagi manusia sejak masa prasejarah sampai sekarang. Keberadaan gua-gua dan ceruk payung (rock shelter) di dalamnya membuka kesempatan bagi manusia prasejarah untuk tinggal sementara atau menetap. Menurut hasil penelitian Harry Widianto, kawasan karst pada bagian utara Pegunungan Meratus menyimpan budaya prasejarah sejak 6.000 tahun lalu yang dikembangkan manusia Australomelanesid, di situs Gua Babi dan Gua Tengkorak (Widianto dan Handini 2003). Manusia prasejarah ini diperkirakan masuk ke Kalimantan dari pantai utara Pulau Jawa, terus bergerak ke arah utara sampai pada kawasan karst di sekitar Desa Muara Uya, Tabalong. Mereka tinggal di Gua Babi dan mengembangkan teknologi penyerpihan preneolitik dengan subsistensi perburuan binatang dan melakukan prosesi penguburan di Gua Tengkorak (Widianto dan Handini 2003).

Jika di bagian utara ada situs prasejarah, bagaimana dengan kawasan karst yang berada pada bagian timur Pegunungan Meratus, apakah pernah dieksplorasi oleh manusia prasejarah pada masa lalu? Pertanyaan ini yang menjadi dasar pelaksanaan penelitian kawasan karst Mantewe (yang berada di bagian timur Pegunungan Meratus) pada tahun 2008 lalu. Hasilnya sungguh mencengangkan, bahwa potensi situs hunian prasejarah pada kawasan karst ini sangat bagus. Beberapa situs gua hunian itu mempunyai sisa-sisa budaya prasejarah ribuan tahun lalu. Situs Gua 
Sugung misalnya, sebuah gua yang cukup besar dengan teras gua yang luas dan lorong gua yang panjang, yang selalu basah dan licin. Gua Sugung dijadikan salah satu tujuan wisata lokal yang sangat diminati penduduk di Desa Mantewe dan sekitarnya. Sisa-sisa hunian prasejarah ditemukan di teras Gua Sugung, sementara di bagian lorong guanya tidak ada indikasi temuan. Situs lain ditemukan di Desa Bulurejo, yaitu situs Gua Payung/Batu Tanjak; di Desa Mantewe ada situs Gua Pembicaraan dan Gua Harimau (Sugiyanto 2008). Kawasan karst yang kemudian menjadi fokus penelitian arkeologi prasejarah adalah kawasan karst yang berada di wilayah Desa Rejosari, yang lokasinya berdekatan dengan kawasan karst Dukuhrejo.

Desa Rejosari merupakan salah satu wilayah desa dalam Kecamatan Mantewe yang mempunyai potensi kawasan karst yang bagus. Kawasan karst di Desa Rejosari terlihat lebih rapat dan bersifat terputus-putus bukan gugusan karst yang memanjang. Kawasan karst yang ada di Desa Rejosari ini mempunyai morfologi yang sama dengan yang ada di Desa Sukadamai dan Mantewe. Secara geomorfologi, kawasan karst Desa Rejosari mempunyai hubungan yang erat dengan kawasan karst Desa Mantewe, karena jaraknya yang sangat berdekatan. Kedekatan lokasi ini yang menimbulkan dugaan akan adanya peninggalan budaya yang sama dalam kawasan karst Desa Rejosari dan Desa Mantewe. Ada kemungkinan budaya prasejarah tersebut berkembang secara luas pada kawasan karst yang berada pada wilayah Mantewe, tersebar sampai di Sukadamai, Bulurejo, Mantewe, Dukuhrejo, dan Rejosari.

Permasalahan utama pada penelitian ini adalah bagaimana potensi prasejarah pada kawasan karst di wilayah Desa Rejosari? Permasalahan utama yang perlu dijawab melalui serangkaian kegiatan penelitian eksplorasi yang dilakukan dengan survei kawasan karst dan ekskavasi arkeologi pada situs-situs terpilih nantinya. Penelitian ini merupakan salah satu bagian dari penelitian kawasan tentang prasejarah Kalimantan Selatan yang berkembang pada Pegunungan Meratus, terutama pada kawasan karst yang berada di bagian tenggara Provinsi Kalimantan Selatan.

\section{METODE}

Penelitian arkeologi prasejarah kawasan karst Rejosari ini menggunakan metode penelitian deskriptif, dengan penalaran induktif. Metode pengumpulan datanya dilakukan dengan survei dan ekskavasi (test pit). Survei dilaksanakan secara random dengan bantuan pemandu dan tenaga lokal setempat dengan penekanan pada pengamatan terhadap gejala-gejala khusus (indikasi hunian) manusia prasejarah yang ada pada gua-gua dan ceruk payung di dalam kawasan karst Rejosari. Selain temuan permukaan, juga dilakukan pengamatan lingkungan dan daya dukung kehidupan lainnya.

Survei dilaksanakan secara cermat, terhadap bentuk (morfologi) gua, kondisi ruangan, lokasi gua, dan arah hadapnya. Gua-gua yang luas, kering, terang karena mendapat sinar matahari yang cukup akan menjadi pilihan utama kelompok manusia prasejarah sebagai tempat tinggal mereka baik sementara maupun menetap (dalam waktu yang lama). Beberapa situs gua yang sudah terdaftar ini, kemudian dipilih dan ditetapkan sebagai situs uji coba dengan melakukan kegiatan penggalian (test pit). Pelaksanaan test pit akan dilakukan dengan cermat dan teliti untuk menjamin terkumpulnya data prasejarah yang ingin dicari pada penelitian ini.

Penelitian ini dilakukan untuk mengetahui persebaran situs-situs gua hunian prasejarah di dalam kawasan karst Desa Rejosari. Data dan informasi ini akan menjadi dasar perencanaan penelitian berikutnya tentang perkembangan budaya prasejarah khususnya pada kawasan karst Mantewe. Budaya prasejarah yang berkembang pada kawasan karst Mantewe ini merupakan salah satu bagian dari sejarah perkembangan manusia prasejarah pada kawasan karst di sekitar Pegunungan Meratus, Kalimantan Selatan secara umum.

\section{HASIL DAN PEMBAHASAN}

\section{Situs Gua Prasejarah di Desa Rejosari}

Secara umum, karakter gua-gua yang ada pada kawasan karst Desa Rejosari mempunyai kesamaan dengan gua-gua pada kawasan karst Desa Dukuhrejo dan Desa Mantewe, yaitu mempunyai banyak pintu masuk, dengan lorong yang berliku dan panjang. Sebagian besar lorong- 
lorong gua mempunyai ukuran yang cukup besar, sehingga nyaman untuk dijelajahi dan diamati morfologi serta lingkungan alam di dalamnya. Selain itu, morfologi ceruk payung yang ada hampir semuanya mempunyai ukuran panjang yang cukup signifikan. Lokasi yang dimanfaatkan sebagai situs yang lebih banyak berupa ceruk yang kondisinya kering dan tidak terlalu luas. Sementara gua-gua yang umumnya mempunyai kondisi layak huni, ternyata tidak semuanya digunakan sebagai situs hunian.

Secara umum kegiatan penelitian berhasil melakukan pengamatan pada 30 gua dan ceruk payung (rock shelter). Berdasarkan pengamatan di lapangan terdapat 23 situs yang mempunyai indikasi hunian prasejarah dan temuan gambar cadas. Situs-situs itu adalah sebagai berikut:

\section{Gua Babi}

Gua Babi secara astronomis berada pada koordinat $03^{\circ} 13^{\prime} 11,91^{\prime \prime}$ LS dan $115^{\circ} 45^{\circ} 01,12^{\prime \prime}$ BT, dengan ketinggian $64 \mathrm{~m}$ dpl (di atas permukaan laut). Gua Babi berada di sekitar perkebunan kelapa sawit milik penduduk setempat bernama Jailani (56 th). Gua Babi mempunyai ukuran panjang $47.56 \mathrm{~m}$, tinggi $10,57 \mathrm{~m}$, dan lebar $10,12 \mathrm{~m}$, dengan arah hadap $135^{\circ}$ (timur tenggara) dan kemiringan lantai gua $18^{\circ}$. Sejak tahun 2017, masyarakat sudah melakukan penambangan guano untuk pupuk tanaman. Hasil survei antara lain menemukan fragmen tengkorak binatang, gigi binatang, tatal batu, batu kapur bulat, fragmen gerabah (bagian badan), dan beberapa cangkang kerang air tawar.

\section{Ceruk Panjang}

Ceruk Panjang berada tepat di sebelah timur Gua Babi, yang secara astronomis berada pada koordinat $03^{\circ} 13^{\prime} 11,76^{\prime \prime} \mathrm{LS}$ dan $115^{\circ} 45^{\prime}$ 59,96" BT, dengan ketinggian $69 \mathrm{~m}$ dpl. Ceruk Panjang mempunyai panjang $12,26 \mathrm{~m}$, tinggi $10,89 \mathrm{~m}$, dan lebar lantai 4,16 m dengan arah hadap mulut ceruk $78^{\circ}$ (timur) dengan kondisi permukaan lantai tidak rata. Temuan permukaan berupa fragmen gerabah (badan) polos dengan ketebalan $0,5 \mathrm{~cm}$ dan tepian berhias dengan ketebalan $0,4 \mathrm{~cm}$, dan cangkang kerang pada permukaan lantai ceruk.

\section{Gua Tujuh Pintu}

Gua ini secara astronomis berada pada koordinat $03^{\circ} 13^{\prime} 16,23^{\prime \prime}$ LS dan $115^{\circ} 44^{\prime} 49,23^{\prime \prime}$ BT dengan ketinggian $65 \mathrm{~m}$ dpl dan hadap $40^{\circ}$. Pintu timur laut mempunyai ruang yang cukup luas dengan kondisi permukaan landai, berukuran panjang 11,53 m, tinggi 4,16 m, dan lebar 10,89 m. Hasil survei menemukan batu inti pada dinding kanan gua.

\section{Ceruk Gambar}

Ceruk Gambar secara astronomis berada pada koordinat $03^{\circ} 13^{\prime} 20,83^{\prime \prime}$ LS dan $115^{\circ} 44^{\prime}$ 54.07" BT dan berada pada ketinggian $63 \mathrm{~m}$ dpl. Ceruk Gambar mempunyai panjang $39,78 \mathrm{~m}$, tinggi 1,95 $\mathrm{m}$ dan lebar 7,59 $\mathrm{m}$ dengan arah hadap mulut $60^{\circ}$ (timur laut). Ceruk ini merupakan ceruk bertingkat di mana pada lantai dasar ditemukan fragmen gerabah dan cangkang kerang, sedangkan pada lantai 2 ditemukan lukisan dinding pada langitlangit gua. Lukisan dinding sebanyak enam figur manusia kangkang dan ayam hutan berwarna hitam, empat lukisan terletak pada langit-langit ceruk yang berjarak 1,8 dari lantai dan 2 berukuran kecil yang terletak pada langit-langit yang berjarak $84 \mathrm{~cm}$ dari lantai ceruk. Kondisi lukisan mulai mengalami pengelupasan. Penjabaran temuan lukisan dinding gua di Ceruk Gambar sebagai berikut.

\section{Lukisan Dinding 1}

Lukisan dinding gua 1 berupa figur manusia dengan kepala yang pada bagian atasnya seperti memiliki rambut/mahkota (Gambar 1). Gambar rambut/mahkota tersebut terdiri dari empat garis dengan posisi (kepala) menghadap ke selatan, pada bagian tangan dan kaki mempunyai empat jari, dengan posisi tangan dan kaki direntangkan. Tubuh berbentuk oval dan secara keseluruhan mempunyai ukuran panjang 45 dan lebar $38 \mathrm{~cm}$.

\section{Lukisan Dinding 2}

Lukisan dinding 2 berupa figur manusia yang mempunyai kepala dengan rambut/mahkota sebanyak empat garis dengan posisi (kepala) menghadap ke selatan (Gambar 2). Figur juga mempunyai dua daun telinga, tangan kanan dengan jari 5 dan tangan kiri dengan jari 4 . Jari kaki kanan ada 5 dan kaki kiri digambarkan dengan posisi menghadap ke samping. Posisi tangan direntangkan dan kaki ditekuk. Bentuk tubuh oval dan secara keseluruhan mempunyai ukuran panjang $40 \mathrm{~cm}$ dan lebar $43 \mathrm{~cm}$. 


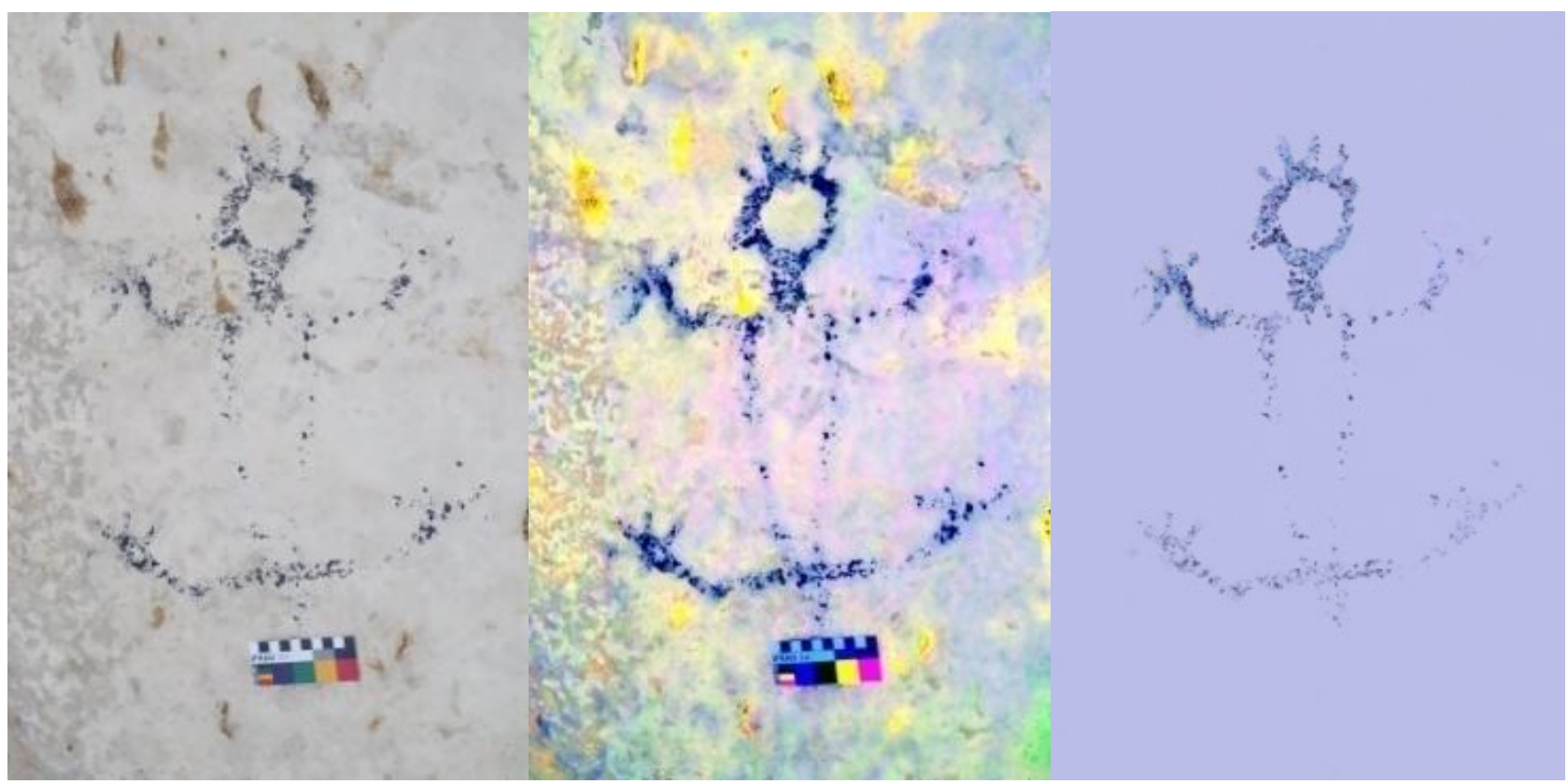

Sumber: Dok. Balar Kalsel 2018

Gambar 1 Lukisan Dinding 1 dan Hasil Pengolahan Gambarnya

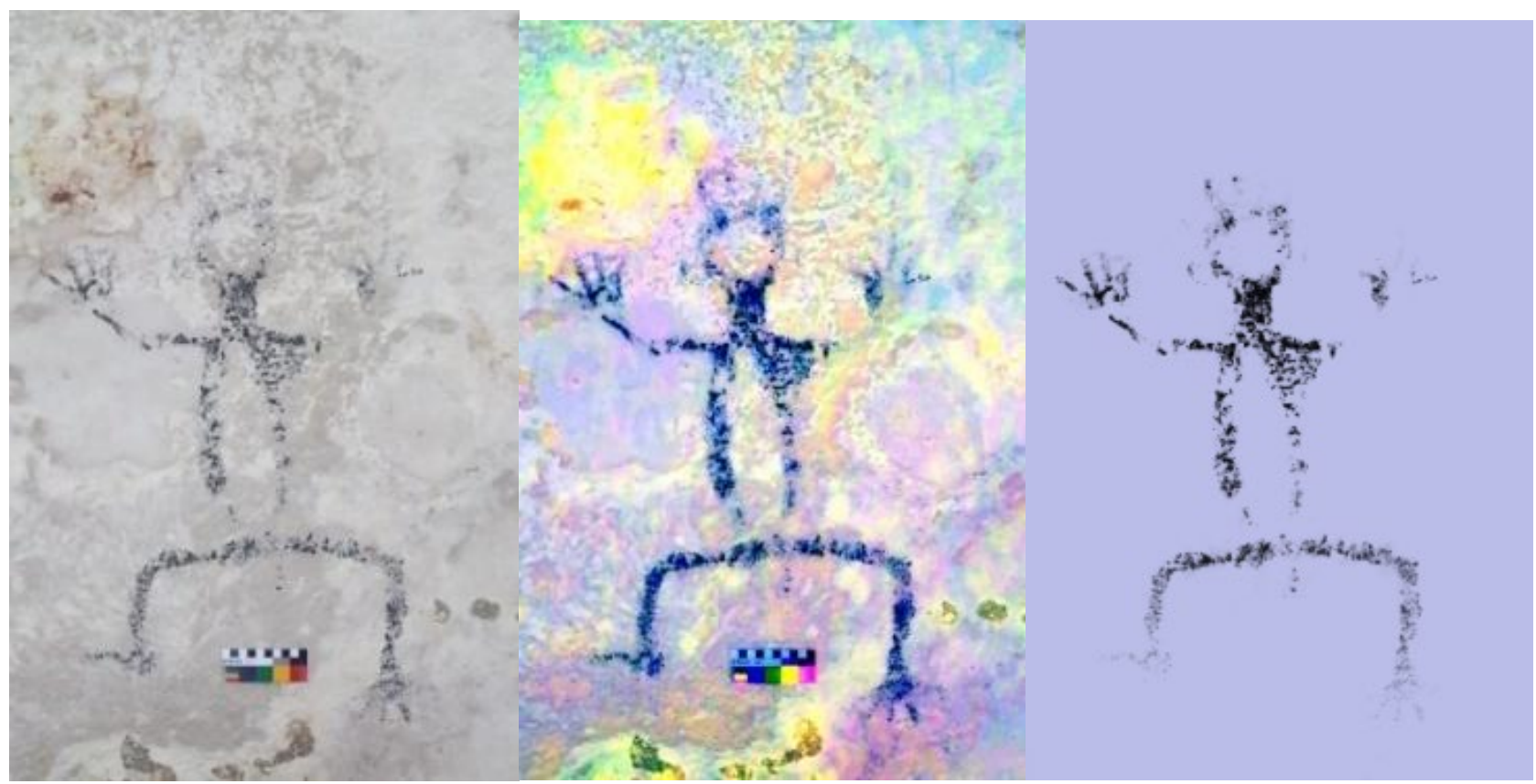

Sumber: Dok. Balar Kalsel 2018

Gambar 2 Lukisan Dinding 2 dan Hasil Pengolahan Gambarnya

\section{Lukisan Dinding 3}

Lukisan dinding 3 merupakan lukisan paling besar di antara lukisan dinding yang ada di Ceruk Gambar. Lukisan dinding 3 adalah figur manusia yang bagian atas kepala memiliki rambut/mahkota sebanyak dua garis dengan posisi (kepala) menghadap ke utara (Gambar 3). Tangan kanan dan kiri digambarkan dengan posisi telapak tangan dikepal. Kaki kanan dan kiri digambarkan dengan posisi menghadap ke samping. Posisi tangan direntangkan dan kaki ditekuk, sementara itu bentuk tubuh berbentuk segitiga dan secara keseluruhan mempunyai ukuran panjang $75 \mathrm{~cm}$ dan lebar $45 \mathrm{~cm}$. 


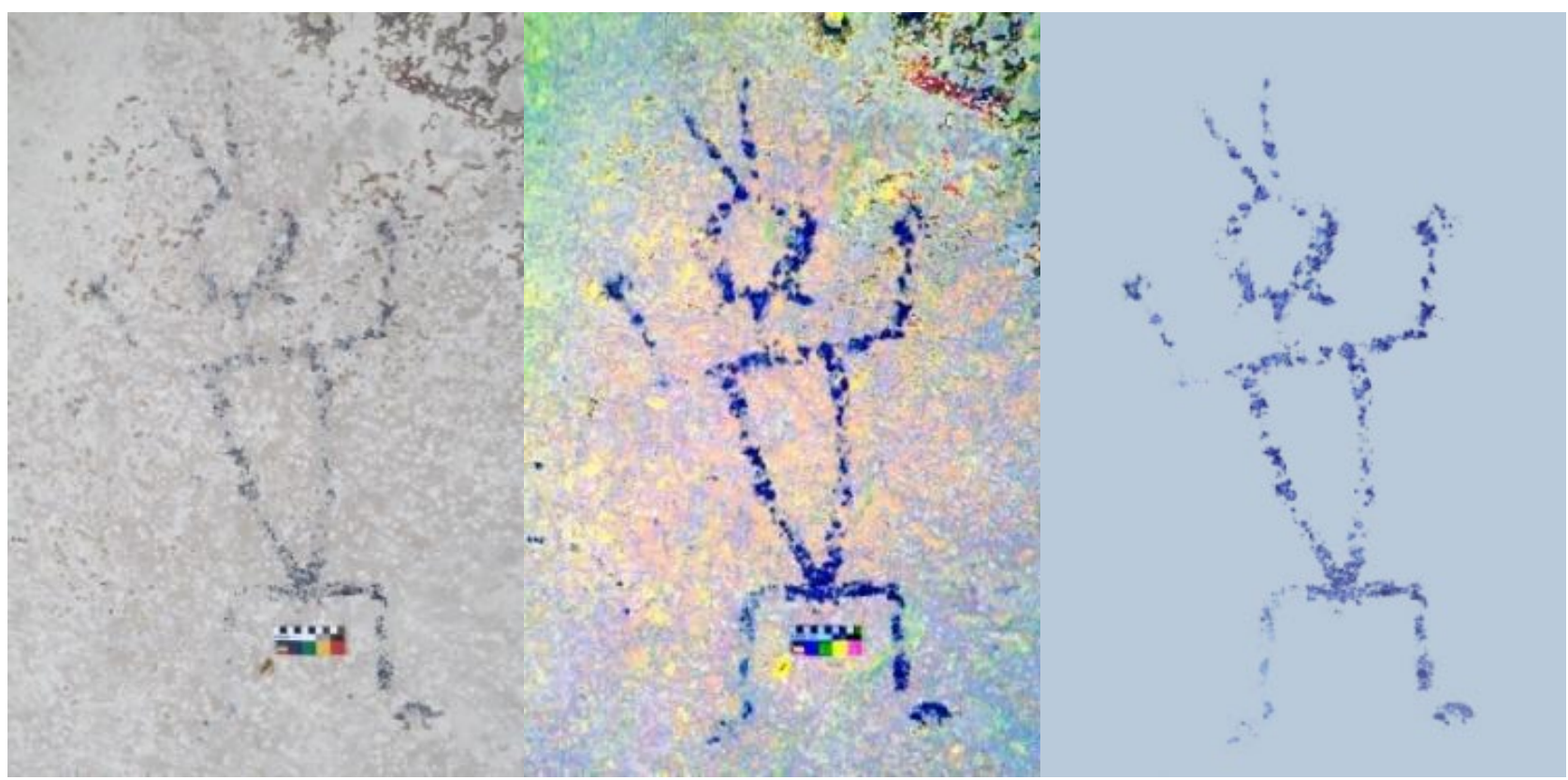

Sumber: Dok. Balar Kalsel 2018

Gambar 3 Lukisan Dinding 3 dan Hasil Pengolahan Gambarnya

\section{Lukisan Dinding 4}

Lukisan dinding 4 berupa figur manusia yang mempunyai ukuran lebih kecil dari lukisan dinding lainnya. Kepalanya tidak mempunyai rambut/mahkota dan posisinya menghadap ke barat. Tangan kanan dan kiri terentang ke atas, tetapi jari-jari tidak digambarkan dengan jelas. Kaki kanan dan kiri digambarkan dengan posisi ditekuk seperti sedang lari/jalan. Bentuk badan digambar berbentuk persegi empat panjang/trapesium dan secara keseluruhan mempunyai ukuran panjang 21 $\mathrm{cm}$ dan lebar $8 \mathrm{~cm}$.

\section{Lukisan Dinding 5}

Lukisan dinding 5 mempunyai ukuran yang lebih kecil dari lukisan 4. Bagian kepala tidak mempunyai rambut/mahkota, dan menghadap ke barat. Pada kepala terdapat mata dan hidung yang digambarkan dengan titik. Tangan kanan dan kiri digambar terentang, bentuk badan segitiga, kaki kanan dan kiri tidak jelas. Secara keseluruhan mempunyai ukuran panjang $17 \mathrm{~cm}$ dan lebar $10 \mathrm{~cm}$.

\section{Lukisan Dinding 6}

Lukisan dinding 6 berupa motif binatang yang menyerupai lukisan ayam jago. Kondisi lukisan sudah rusak, hanya terlihat badan, kaki dan ekornya yang berupa tiga garis lengkung.

\section{Gua Binjai}

Gua Binjai secara administratif berada di Desa Rejosari, Kecamatan Batulicin, Kabupaten Tanah Bumbu dan secara astronomis terletak $03^{\circ}$ 13' 18,30" LS dan $115^{\circ} 45^{\prime}$ 01,59" BT dan berada pada ketinggian $51 \mathrm{~m}$ dpl. Gua Binjai mempunyai tiga pintu masuk yang terletak di sisi timur, barat, dan di antara pintu timur dan barat. Kondisi gua lembap, dikarenakan gua ini masih aktif. Survei permukaan menemukan banyak data arkeologi di pintu gua yang memiliki arah hadap $210^{\circ}$ (barat daya). Pintu ini mempunyai panjang $47,15 \mathrm{~m}$, tinggi $7,25 \mathrm{~m}$, dan lebar $4.67 \mathrm{~m}$. Temuan berupa alat serpih batu besar, serpih batu kuarsa, serpih belum dipakai, tatal batu, dan cangkang kerang ditemukan tersebar di beberapa tempat pada area ini.

\section{Gua Tembus}

Gua Tembus secara astronomis terletak pada koordinat $03^{\circ} 13^{\prime} 03,22^{\prime \prime}$ LS dan $115^{\circ} 45^{\prime} 20,05^{\prime \prime}$ BT, berada pada ketinggian $55 \mathrm{~m}$ dpl. Gua Tembus mempunyai ukuran panjang $28,82 \mathrm{~m}$, tinggi $6,67 \mathrm{~m}$ dan lebar $7,23 \mathrm{~m}$. dengan arah hadap mulut gua $130^{\circ}$ (timur tenggara), kondisi permukaan landai dan sedikit lembab. Temuan permukaan yang ditemukan pada dinding gua berupa serpih, bilah, gigi, tulang, dan fragmen gerabah.

\section{Ceruk Panjang 2}

Ceruk Panjang 2 berada tidak jauh dari Gua Tembus ke arah timur. Ceruk ini secara astronomis 
terletak pada koordinat $03^{\circ} 13^{\prime} 01,88^{\prime \prime}$ LS dan $115^{\circ}$ 45' 20.62" BT, dengan ketinggian $67 \mathrm{~m}$ dpl. Ceruk Panjang merupakan ceruk yang memanjang ke samping, dengan panjang $25,98 \mathrm{~m}$, tinggi langitlangit 5,65 $\mathrm{m}$, dan lebar $9,01 \mathrm{~m}$, dengan arah hadap ceruk $187^{\circ}$ (selatan). Ceruk ini memiliki permukaan lantai yang miring. Hasil survei menemukan serpih, fragmen tulang, fragmen gerabah, dan cangkang kerang di permukaan lantainya.

\section{Gua Lumut}

Gua Lumut atau Gua Meliau, secara astronomis terletak pada $03^{\circ} 12^{\prime} 58,33^{\prime \prime}$ LS dan $115^{\circ}$ $45^{\prime}$ 20,58" BT, dan berada pada ketinggian $62 \mathrm{~m}$ dpl. Gua Lumut mempunyai ukuran panjang 22,44 $\mathrm{m}$, tinggi $12,58 \mathrm{~m}$ dan lebar $6,5 \mathrm{~m}$ dengan arah hadap mulut gua $108^{\circ}$ (timur). Kondisi gua sangat lembab dan banyak bongkahan batu/boulder di depan gua, sehingga hampir sebagian dinding gua ditumbuhi lumut yang cukup tebal. Temuan permukaan berupa serpih, tulang, fragmen gerabah, dan cangkang kerang ditemukan berada di dekat bongkahan batu.

\section{Ceruk Luwa}

Ceruk Luwa berada pada koordinat $03^{\circ} 12^{\prime}$ $57,68^{\prime \prime}$ LS dan $115^{\circ} 45^{\prime} 21,31$ " BT dan berada pada ketinggian $62 \mathrm{~m}$ dpl. Ceruk Luwa merupakan ceruk yang memanjang ke samping berukuran panjang $14,17 \mathrm{~m}$, tinggi $12,87 \mathrm{~m}$ dan lebar 7,64 $\mathrm{m}$ dengan arah hadap ceruk $182^{\circ}$ (selatan). Kondisi permukaan lantai miring dan sekarang digunakan sebagai kandang sapi.Temuan permukaan antara lain fragmen tulang, fragmen gerabah, dan cangkang kerang.

\section{Gua Sengon}

Gua Sengon secara astronomis terletak pada koordinat $03^{\circ} 12^{\prime} 53,09^{\prime \prime}$ LS dan $115^{\circ} 45^{\prime} 13,95^{\prime \prime}$ BT dan berada pada ketinggian $75 \mathrm{~m}$ dpl. Gua Sengon mempunyai panjang $10,1 \mathrm{~m}$, tinggi $5,37 \mathrm{~m}$, dan lebar 5,02 $\mathrm{m}$ dengan arah hadap mulut gua $104^{\circ}$ (selatan). Permukaan lantainya landai dengan banyak bongkahan batu/boulder dan temuan permukaan berupa serpih, fragmen gerabah, dan cangkang kerang.

\section{Gua Batu Kapal}

Gua Batu Kapal secara astronomi terletak pada koordinat ${ }^{\circ} 12^{\prime} 57,70^{\prime \prime}$ LS dan $115^{\circ} 45^{\prime} 48,22^{\prime \prime}$ BT dan berada pada ketinggian $50 \mathrm{~m}$ dpl. Gua Batu
Kapal mempunyai panjang $21,08 \mathrm{~m}$, tinggi $9,75 \mathrm{~m}$, dan lebar $10,88 \mathrm{~m}$ dengan arah hadap gua $344^{\circ}$ (utara). Kondisi lantai gua banyak terdapat batubatu atau boulder bekas penggalian. Pada tahun 2008 ceruk ini pernah disurvei oleh Balar Kalimantan Selatan.

\section{Ceruk Pilar}

Ceruk Pilar secara astronomis terletak pada koordinat $03^{\circ} 12^{\prime}$ 57,97" LS dan $115^{\circ} 45^{\prime}$ '49,25” BT dan berada pada ketinggian $40 \mathrm{~m}$ dpl. Ceruk Pilar tahun 2008 pernah disurvei oleh Balai Arkeologi Kalimantan Selatan. Kondisi permukaan landai dengan ukuran panjang 14,91 m, tinggi 2,3 m, dan lebar 5,14 dengan arah hadap ceruk $152^{\circ}$ (timur tenggara), temuan permukaan berupa serpih, batu pukul, fragmen keramik, fragmen gerabah, manikmanik, dan cangkang kerang.

\section{Gua Halte}

Gua Halte secara astronomis terletak pada koordinat $03^{\circ} 12^{\prime} 53,30^{\prime \prime}$ LS dan $115^{\circ} 45^{\prime} 35,63^{\prime \prime}$ BT dan berada pada ketinggian $44 \mathrm{~m}$ dpl. Gua Halte mempunyai ukuran panjang 22,46 m, tinggi 2,14 m dan lebar 12,09 $\mathrm{m}$ dengan arah hadap mulut gua $238^{\circ}$ (barat daya), Gua Halte mempunyai ukuran yang tidak terlalu besar dan pada bagian dalam terdapat lorong-lorong kecil yang sempit. Temuan permukaan yang ditemukan antara lain fragmen gerabah, gigi seri, hematit, cangkang kerang. Survei juga menemukan lukisan dinding gua berupa manusia kangkang sebanyak dua gambar. Deskripsi lukisan dinding di Gua Halte adalah sebagai berikut.

\section{Lukisan Dinding 1}

Lukisan dinding 1 berada pada langit-langit sebelah kiri gua yang berjarak 40 dari permukaan lantai. Lukisan dinding berupa manusia kangkang, bagian kepala mulai mengalami pemudaran sehingga bentuk kepalanya tidak dapat diidentifikasi bentuknya. Posisi (kepala) menghadap ke barat daya, tangan kanan dan kiri digambarkan terentang dan telapak tangan dikepal. Bentuk badan persegi empat, dan kaki kanan dan kiri digambarkan terbuka lebar dengan posisi kaki menghadap ke samping. Secara umum bentuk lukisan digambar seperti orang yang sedang berjalan dan mempunyai panjang $33 \mathrm{~cm}$ dengan lebar $31 \mathrm{~cm}$. 


\section{Lukisan Dinding 2}

Lukisan dinding 2 berada pada langit-langit gua yang berjarak $2 \mathrm{~m}$ dari permukaan lantai. Lukisan dinding ini kurang jelas karena sudah aus. Oleh karena itu, lukisan dinding sulit untuk diamati.

\section{Gua Undur-Undur}

Gua Undur-undur secara astronomis terletak pada koordinat $03^{\circ} 12^{\prime} 51,81^{\prime}$ LS dan $115^{\circ} 45^{\prime} 29,49^{\prime \prime}$ BT dan berada pada ketinggian $57 \mathrm{~m}$ dpl. Kondisi permukaan lantai tidak rata dan terdapat bongkahan batu, dengan temuan permukaan berupa fragmen gerabah dan cangkang kerang.

\section{Ceruk Tingkat}

Ceruk Tingkat secara astronomis terletak pada koordinat $03^{\circ} 13^{\prime} 22,08^{\prime \prime}$ LS dan $115^{\circ} 44^{\prime} 46,58^{\prime \prime}$ BT dan berada pada ketinggian $44 \mathrm{~m}$ dpl. Ceruk Tingkat merupakan ceruk yang memanjang dan mempunyai tingkat/lantai atas. Ceruk ini memiliki ukuran panjang $6,69 \mathrm{~m}$, tinggi 2,12 $\mathrm{m}$, dan lebar $2,54 \mathrm{~m}$ dengan arah hadap ceruk $273^{\circ}$ (barat). Lantai ceruk bagian bawah terdapat ruangan yang pada permukaan lantainya ditemukan fragmen gerabah dan cangkang kerang. Sementara itu, lantai ceruk di bagian atas ditemukan serpih.

\section{Ceruk Musang}

Ceruk Musang secara astronomis terletak pada koordinat $03^{\circ} 13^{\prime} 18,93^{\prime \prime}$ LS dan $11544^{\prime}$ 45,52" BT dengan ketinggian $55 \mathrm{~m}$ dpl. Ceruk ini mempunyai ukuran yang tidak terlalu besar dengan kondisi permukaan landai.Temuan permukaan berupa fragmen gerabah (badan) polos dengan ketebalan $0,3 \mathrm{~cm}$ yang ditemukan pada sela-sela dinding.

\section{Gua Gandum}

Gua Gandum secara astronomis terletak pada koordinat $03^{\circ} 13^{\prime} 19,08^{\prime \prime}$ LS dan $115^{\circ} 45^{\prime} 10,70^{\prime \prime}$ BT dan berada pada ketinggian $61 \mathrm{~m}$ dpl. Gua Gandum mempunyai panjang $51,42 \mathrm{~m}$, tinggi 7,14 $\mathrm{m}$, dan lebar 16,8 $\mathrm{m}$ dengan arah hadap mulut gua $182^{\circ}$ (selatan). Kondisi lantai cukup landai dan ditemukan serpih, tatal batu, tulang, fragmen gerabah, dan cangkang kerang.

\section{Gua Tampurian}

Gua Tampurian secara astronomis terletak pada koordinat $03^{\circ} 13^{\prime} 12,83^{\prime \prime}$ LS dan $115^{\circ} 45^{\prime} 04,1^{\prime \prime}$ BT dan berada pada ketinggian $71 \mathrm{~m}$ dpl. Gua
Tampurian mempunyai panjang $10,57 \mathrm{~m}$, tinggi 2,85 m, dan lebar 5,14 m dengan arah hadap mulut gua $205^{\circ}$ (barat daya), Kondisi gua tidak terlalu besar dengan permukaan lantai landai. Temuan permukaan yang diperoleh pada lantai berupa serpih, tulang, fragmen gerabah, dan cangkang kerang.

\section{Gua Luwa}

Gua Luwa secara astronomis terletak pada koordinat $03^{\circ} 12^{\prime} 59,1^{\prime \prime}$ LS dan $115^{\circ} 44^{\prime} 41,94^{\prime \prime}$ BT dan berada pada ketinggian $71 \mathrm{~m}$ dpl. Gua Luwa mempunyai ukuran panjang tinggi $106,6 \mathrm{~m}$, tinggi $8,87 \mathrm{~m}$, dan lebar $24,31 \mathrm{~m}$ dengan arah hadap mulut gua $225^{\circ}$ (barat daya). Gua ini mempunyai ruang yang luas dengan lorong-lorong yang memanjang di bagian kiri gua dan mempunyai lantai bertingkat/atas pada ruang utama, sedangkan sisi kanan terdapat teras yang cukup panjang. Pada permukaan lantai ditemukan serpih, fragmen gerabah, dan cangkang kerang, sedangkan rock art ditemukan di teras sebelah kanan gua dekat dekat aliran sungai bawah tanah. Lukisan dinding gua ada empat yang digambar pada dinding gua dengan warna hitam. Lukisan itu adalah:

\section{Lukisan Dinding 1}

Lukisan dinding 1 berupa gambar garis lingkaran berdiameter $13 \mathrm{~cm}$, bentuk lukisan ini menyerupai kepala manusia, dan pada bagian bawah berjarak $30 \mathrm{~cm}$ terdapat gambar setengah lingkaran dengan ukuran lebih kecil sebanyak 4 yang digambar secara bersusun.

\section{Lukisan Dinding 2}

Lukisan dinding 2 menyerupai laba-laba yang terdiri atas kepala berdiameter $7,5 \mathrm{~cm}$, badan berukuran lebar $13 \mathrm{~cm}$, tinggi $11 \mathrm{~cm}$, dan kaki digambarkan dengan garis gerigis yang memanjang berukuran $55 \mathrm{~cm}$.

\section{Lukisan dinding 3}

Lukisan dinding 3 menyerupai gambar ayam, berukuran panjang $23 \mathrm{~cm}$ dan pada bagian ekor digambar dengan 6 garis lengkung. Gambar ayam memang banyak ditemukan di gua-gua yang ada di Pegunungan Meratus seperti di Liang Bangkai.

\section{Lukisan Dinding 4}

Lukisan dinding 4 berupa manusia kangkang pada bagian atas kepala memiliki mata dengan 
posisi (kepala) menghadap ke atas, tangan kanan ditekuk menghadap ke bawah dengan telapak tangan dikepal dan tangan kiri ditekuk ke atas, dengan posisi telapak tangan terbuka sehingga jari tangan kelihatan ada lima jari. Kaki kanan dan kiri digambarkan dengan posisi ditekuk menghadap ke samping, badan berbentuk oval, lukisan ini mempunyai panjang $43 \mathrm{~cm}$ dan lebar $24,5 \mathrm{~cm}$.

\section{Gua Cakrawala}

Gua Cakrawala secara astronomis terletak pada koordinat $03^{\circ} 12^{\prime} 56,67^{\prime \prime} \mathrm{LS}$ dan $115^{\circ} 44^{\prime} 39,22^{\prime \prime}$ BT dan berada pada ketinggian $67 \mathrm{~m}$ dpl. Gua Cakrawala mempunyai panjang 39,49 m, tinggi 6,7 $\mathrm{m}$, dan lebar 19,09 m dengan arah hadap mulut gua $232^{\circ}$ (barat daya), kondisi permukaan landai dan ditemukan serpih fragmen gerabah dan cangkang kerang.

\section{Gua Belimbing}

Gua Belimbing secara astronomis terletak pada $03^{\circ} 12^{\prime} 54,75^{\prime \prime}$ LS dan $115^{\circ} 44^{\prime} 38,30 "$ BT dan berada pada ketinggian $63 \mathrm{~m}$ dpl. Gua Belimbing mempunyai panjang $29,23 \mathrm{~m}$, tinggi $2,45 \mathrm{~m}$ dan lebar 4,92 $\mathrm{m}$ dengan arah hadap mulut gua $177^{\circ}$ (selatan), kondisi permukaan landai dan ditemukan serpih, fragmen serpih, batu inti, tatal batu, tulang (kura-kura), fragmen gerabah, fragmen keramik, dan cangkang kerang.

\section{Gua Rotan}

Gua Rotan secara astronomis terletak pada koordinat $03^{\circ} 12^{\prime} 52,26^{\prime \prime}$ LS dan $115^{\circ} 45^{\prime} 08,65^{\prime \prime}$ BT dan berada pada ketinggian $71 \mathrm{~m}$ dpl. Gua Rotan mempunyai panjang $98,96 \mathrm{~m}$, tinggi $5,79 \mathrm{~m}$, dan lebar $12,01 \mathrm{~m}$ dengan arah hadap mulut gua $43^{\circ}$ (timur laut), kondisi permukaan gua landai dan pada bagian tengah terdapat lorong yang tembus ke aliran sungai bawah tanah, temuan permukaan berupa fragmen gerabah, fragmen keramik, dan cangkang kerang.

\section{Gua Sirih}

Gua Sirih secara astronomis terletak pada koordinat $03^{\circ} 12^{\prime} 54,39^{\prime \prime} \mathrm{LS}$ dan $115^{\circ} 44^{\prime} 56,32$ " BT dan berada pada ketinggian $77 \mathrm{~m}$ dpl. Gua Sirih mempunyai panjang $71,77 \mathrm{~m}$, tinggi $8,39 \mathrm{~m}$, dan lebar $50 \mathrm{~m}$ dengan arah hadap mulut gua $305^{\circ}$ (barat laut), kondisi permukaan landai dengan pelataran yang cukup luas. Pada bagian tengah gua terdapat bongkahan batu/boulder dan temuan 80 permukaan berupa batu pemukul, serpih belum dipakai, batu inti, serpih dipakai, serpih, bilah, tatal batu, batu pemukul andesit, tulang, hematite, fragmen gerabah, dan cangkang kerang.

\section{Potensi Prasejarah dan Temuan Lukisan Dinding Gua di Desa Rejosari}

Secara umum, pada kawasan karst Desa Rejosari mempunyai potensi gua-gua dan ceruk payung yang baik. Karakter gua-gua yang ada pada umumnya mempunyai lorong-lorong panjang berliku dan seringkali tembus sampai pada bagian lereng gunung lainnya. Bahkan ada beberapa guagua besar yang sebenarnya mempunyai potensi wisata alam yang baik, tetapi oleh sebagian penduduk dimanfaatkan sebagai tempat untuk mengambil pupuk (kotoran kelelawar/guano) sebagai pupuk untuk tanaman kelapa sawit yang mereka kembangkan saat ini.

Prospek situs gua atau ceruk prasejarah pada kawasan karst Desa Rejosari cukup bagus dengan total situs ditemukan adalah 23 gua. Situssitus itu tersebar secara acak pada lereng-lereng bawah bukit karst yang berada pada kawasan karst Rejosari. Untuk sementara potensi situs gua-gua yang berada di tengah dan atas bukit karst belum diketahui dan belum dikunjungi. Secara sepintas, terlihat beberapa lubang gua yang cukup besar berada pada bagian tengah dan puncak bukit-bukit karst tersebut, seolah-olah menantang untuk dikunjungi pada penelitian berikutnya.

Pengamatan pada 23 situs gua dan ceruk tersebut, kemudian dilanjutkan dengan pemilihan satu situs yang diteliti lebih lanjut dengan ekskavasi arkeologi. Metode ekskavasi ini merupakan satu cara untuk membuktikan kebenaran suatu situs, dengan test pit (penggalian percobaan) pada situs Ceruk Pilar.

Hasil penggalian menunjukkan bahwa situs Gua Pilar merupakan tempat tinggal manusia prasejarah pendukung budaya mesolitik di kawasan karst Pegunungan Meratus bagian Tenggara (timur selatan). Masa penghunian gua-gua itu tampaknya diikuti dengan perkembangan budaya rock art khusus warna hitam yang ditemukan di Ceruk Gambar, Gua Luwa, dan Gua Halte. Gambargambar yang ditemukan di sini pada umumnya mempunyai ukuran yang besar dan digambarkan pada langit-langit gua atau ceruk. Temuan rock art yang dilukiskan dengan warna hitam menambah 
jumlah situs yang ada. Sebelumnya situs rock art ini ditemukan pada kawasan karst Desa Dukuhrejo dan Desa Bulurejo (Oktrivia, Hindarto, dan Herwanto 2013; Sugiyanto, Jatmiko, dan Cahyaningtyas 2013).

Berdasarkan artefak yang ditemukan dari survei dan test pit, jelas menggambarkan bahwa budaya prasejarah yang berkembang pada kawasan karst Desa Dukuhrejo mempunyai kesamaan dengan yang ditemukan di Desa Dukuhrejo. Secara geografis, kedua kawasan karst ini memang berada pada satu wilayah administrasi kecamatan yang sama, yaitu Kecamatan Mantewe. Untuk kawasan karst yang ada di Desa Dukuhrejo, budaya prasejarah itu berpusat di situs Liang Bangkai 1, dengan situs kuburnya di Liang Bangkai 10, dan beberapa situs rock art seperti situs Liang Buaya, situs Ceruk Bangkai 11 dan 12, situs Liang Kacamata, dan situs Liang Besar. Pola pemanfaatan ruang pada kawasan karst di Desa Rejosari, kurang lebih sama. Situs hunian yang paling potensi adalah Ceruk Pilar, kemudian ada tiga situs ceruk lainnya yang mempunyai gambar. Warna gambar pada kawasan karst Rejosari sama dengan yang ditemukan di Dukuhrejo, yaitu warna hitam. Semua gambar dengan warna hitam ini mempunyai ukuran yang lebih besar jika dibandingkan dengan gambar-gambar pada umumnya di Dukuhrejo.

Tampaknya budaya rock art yang berkembang pada situs-situs prasejarah di bagian tenggara Pegunungan Meratus ini hampir semuanya menggunakan warna hitam. Selain ditemukan pada kawasan karst di Kabupaten Tanah Bumbu, budaya rock art warna hitam juga ditemukan pada kawasan karst di Kabupaten Kotabaru. Situs Gua Batu Batulis di Desa Hampang, Kecamatan Hampang, merupakan situs rock art warna hitam pertama yang ditemukan (Hartatik 2015). Pada tahun 2018, Nia Marniati dan tim menemukan gambar-gambar dengan warna hitam pada kawasan karst di Kabupaten Kotabaru yang lainnya. Di antara temuan rock art tersebut, ada temuan yang sangat berbeda dan menarik untuk diteliti lebih lanjut, yaitu penemuan gambar cap tangan positif dengan warna merah pada situs Ceruk Rasidi (Kecamatan Kelumpang Barat, Kabupaten Kotabaru) (Fajari dkk. 2018). Temuan cap tangan warna merah ini membuka cakrawala baru tentang perkembangan budaya rock art di wilayah Kalimantan Selatan bagian tenggara.
Menarik untuk diteliti lebih lanjut, apakah cap tangan tersebut memang berasal dari masa prasejarah? Jika memang benar berasal dari masa prasejarah, berarti ada dua pendukung budaya rock art yang berkembang di wilayah ini, satu pendukung rock art dengan warna hitam yang mungkin kronologinya lebih muda, satu lagi pendukung budaya rock art dengan warna merah yang mungkin lebih tua kronologinya. Satu data pendukung yang penting untuk diperhatikan adalah penemuan gambar cap tangan di situs Liang Bangkai 10 oleh tim delineasi Balai Pelestarian Cagar Budaya Kalimantan Timur tahun 2019 (Nur dkk. 2019). Mereka menemukan gambar cap tangan yang sudah "pudar" warnanya pada langit-langit gua Liang Bangkai 10. Kondisi gambar tidak lengkap, hanya terdiri dari tiga jari, yang terlihat jelas dengan bantuan analisis Dstrech.

Apakah ini pertanda "dominasi" masyarakat pendukung budaya rock art warna hitam yang berkembang di wilayah ini? Untuk diketahui, temuan situs rock art dengan warna hitam, juga ditemukan pada wilayah Kalimantan Barat, di situs Liang Kaung (Fage, Chazine, dan Setiawan 2010), dan situs-situs di Kalimantan Timur, Kawasan Sangkulirang Mangkalihat, seperti Liang Sara, Gua Beloyot dan Gua Mardua (Fage dkk. 2010; Lukito dan Susanto 2001; Sugiyanto 2010a; 2010b). Menarik untuk diketahui bagaimana hasil penelusuran budaya prasejarah pada kawasan karst di Kecamatan Mantewe, Kabupaten Tanah Bumbu, khususnya yang berkaitan persebaran budaya prasejarah dan rock art serta kronologi budaya yang ada di dalamnya.

Selain menyimpan sumber daya arkeologi seperti yang diuraikan di atas, kawasan karst Rejosari juga menarik perhatian banyak pihak untuk mengeksplorasinya. Sumber daya batu kapur sebagai salah satu jenis bahan tambang galian $C$, sudah dilakukan oleh sekelompok masyarakat pada beberapa gua. Kegiatan yang paling mengganggu kelestarian gua-gua dan ceruk pada kawasan Rejosari selain pertambangan batu kapur adalah penggalian tanah untuk dijadikan pupuk tanaman murah karena mengandung guano. Gua Babi merupakan salah satu gua yang dieksplorasi guanonya secara intensif dalam beberapa tahun belakangan ini. Kiranya sosialisasi tentang nilai penting kawasan karst dengan gua-gua dan ceruk yang ada di dalamnya perlu lebih sering dilakukan agar pengertian dan pengetahuan masyarakat 
tentang pentingnya kawasan karst dan nilai sejarah budaya yang ada di dalamnya bisa meningkat dan menjadikan mereka lebih perhatian terhadap kelestarian dan pelestarian lingkungan karst serta situs yang ada di dalamnya.

\section{PENUTUP}

Berdasarkan uraian dan penjelasan yang sudah disampaikan pada bagian pembahasan, jelas bahwa kawasan karst yang ada di wilayah Desa Rejosari, Kecamatan Mantewe, Kabupaten Tanah Bumbu, Provinsi Kalimantan Selatan, mempunyai potensi situs prasejarah yang cukup bagus. Situs-situs prasejarah yang ada di wilayah ini antara lain situs hunian prasejarah yang diwakili secara jelas oleh Ceruk Pilar, dan situs rock art dengan warna hitam, seperti situs Ceruk Gambar, Gua Halte, dan Gua Luwa. Artefak prasejarah yang ditemukan dari hasil temuan permukaan (survei), didukung dengan temuan hasil penggalian percobaan pada situs Ceruk Pilar, jelas menunjukkan bahwa kehidupan prasejarah memang pernah terjadi pada beberapa situs gua dan ceruk di wilayah ini, terutama yang terbukti pada situs Ceruk Pilar.

Oleh karena itu, keberadaan situs-situs gua dan ceruk pada kawasan karst Desa Rejosari ini perlu dilindungi dan dilestarikan, sesuai dengan amanat Undang Undang Republik Indonesia Nomor 11 Tahun 2010 tentang Cagar Budaya. Hasil penelitian ini dapat dipergunakan untuk merencanakan pengelolaan situs-situs tersebut dengan baik dan terpadu dari semua pihak yang mempunyai kepentingan pada kawasan karst tersebut, terutama Pemerintah Daerah Kabupaten Tanah Bumbu yang mempunyai wewenang dalam pengelolaan Cagar Budaya.

\section{DAFTAR PUSTAKA}

Fage, Luc-Henri, Jean Michel Chazine, dan Pindi Setiawan. 2010. Borneo: Memory of the Caves . Le Jonty, F82160 Caylus, Prancis: Le Kalimanthrope.

Fajari, Nia Marniati Etie, Wasita, Eko Herwanto, Bambang Sugiyanto, Gregorius Dwi Kuswanta, Thomas Suryono, dan Muhammad Wisnu Wibisono. 2018. "Eksplorasi Arkeologi Kawasan Karst Pegunungan Meratus di Kabupaten Kotabaru, Kalimantan Selatan." Laporan Penelitian Arkeologi. Banjarbaru: Balai Arkeologi Kalimantan Selatan.

Hartatik. 2015. "Religi dan Peralatan Tradisional Suku Dayak Meratus di Kabupaten Kotabaru, Kalimantan Selatan." Kindai Etam 1(1): 95120.

Lukito, Nugroho Harjo dan Nugroho Nur Susanto. 2001. "Penelitian Eksplorasi Arkeologi Pantai Timur Kalimantan Timur." Laporan Penelitian Arkeologi. Banjarbaru: Balai Arkeologi Banjarmasin.

Nur, Muhammad, Tisna Arif Ma'rifat, Etha Sriputri, Rizky Karunia Aria Wibawa, Rizki Ramadhani, dan Indah Yulyantina. 2019. Eksplorasi Karst Mantewe di Kecamatan Mantewe Kabupaten Tanah Bumbu Provinsi Kalimantan Selatan. Samarinda: Balai Pelestarian Cagar Budaya.

Oktrivia, Ulce, Imam Hindarto, dan Eko Herwanto. 2013. "Potensi Arkeologi di Sekitar Bukit Ulin
Kecamatan Mantewe Kabupaten Tanah Bumbu." Laporan Penelitian Arkeologi. Banjarbaru: Balai Arkeologi Banjarmasin.

Sugiyanto, Bambang. 2008. "Penelitian Eksploratif

Gua-Gua Prasejarah di Kabupaten Tanah

Bumbu, Kalimantan Selatan." Laporan

Penelitian Arkeologi. Banjarbaru: Balai Arkeologi Banjarmasin.

Sugiyanto, Bambang. 2010a. "Gambar Cadas di Gua Mardua, Kalimantan Timur." Naditira Widya 4(2): 207-218.

Sugiyanto, Bambang. 2010b. "Penelitian Survei Gua-gua Prasejarah di Kawasan Karst Merabu-Mapulu, Kecamatan Kelay, Kabupaten Berau, Kalimantan Timur." Laporan Penelitian Arkeologi. Banjarbaru: Balai Arkeologi Banjarmasin.

Sugiyanto, Bambang, Jatmiko, dan Yuka Nurtanti Cahyaningtyas. 2013. "Survei dan Ekskavasi Situs Liang Bangkai Desa Dukuhrejo, Kecamatan Mantewe, Kabupaten Tanah Bumbu, Kalimantan Selatan." Laporan Penelitian Arkeologi. Banjarbaru: Balai Arkeologi Banjarmasin.

Widianto, Harry dan Retno Handini. 2003. "Karakteristik Budaya Prasejarah di Kawasan Gunung Batubuli, Kalimantan Selatan: Mekanisme Hunian Gua Pasca-Plestosen." Berita Penelitian Arkeologi 12: 1-91. 